\title{
Gentrificación migratoria en San Miguel de Allende, Guanajuato
}

Dra. Marina Inés de la Torre

Universidad de Guanajuato

Email: marinadlt8@hotmail.com

\section{RESUMEN}

Se analiza el caso de la localidad de San Miguel de Allende, cuyas claves de comprensión residen en dos de sus principales atributos: el alto valor de su patrimonio edificado y su potencial migratorio. Decodificar ambas claves, se hace imprescindible para la comprensión de procesos de gentrificación, cuyas características resultan muy propias y distintivas de esta localidad, si las comparamos con otras centralidades patrimoniales del mismo estado. En el caso de estudio, los turistas dejan de ser flotantes o temporales y se convierten en residentes (inmigrantes), conformando una nueva clase social, cuyo impacto en el entorno local, tanto social como construido, resulta interesante de analizar.

Palabras clave: Gentrificación, Turismo, Migración

\section{Introducción}

Actualmente la promoción del turismo cultural es, entre otros, uno de los factores determinantes para la renovación de los centros históricos de valor patrimonial. La actividad turística demanda un conjunto de servicios y equipamientos, como así también la puesta en valor del patrimonio edificado. La emergencia de nuevos actores (turistas) con cuotas diferenciales de poder (mayores), exacerba la disputa por la apropiación social del espacio urbano; disputa ésta, que con frecuencia impone la presencia de aquellos actores mejor posicionados y el desplazamiento de los residentes de menores recursos. Sin embargo, la emergencia del turismo no explica por sí solo estos procesos de renovación urbana en una centralidad histórica. En tal sentido, la dinámica urbana del centro histórico de San Miguel de Allende, sugiere un tipo de gentrificación particular que podríamos denominar gentrificación migratoria, en cuyo proceso, participan los turistas extranjeros, devenidos en residentes privilegiados de la ciudad. El signo (positivo/negativo) del impacto de estos procesos, está estrechamente ligado al nivel de concentración de extranjeros residentes en la localidad, como así también a las características que asume la convivencia entre locales e inmigrados. 
Para el abordaje del problema planteado, se proponen dos vertientes de entrada: desde la cuestión territorial y física del entorno construido, y desde la cuestión social en un contexto de identidades plurales. En este último caso, resulta importante identificar las estrategias de integración al medio local, por parte del grupo de residentes extranjeros, como así también, indagar en la percepción que el residente local tiene en relación a la comunidad inmigrante.

En las páginas siguientes, se presentan selectivamente los constructos teóricos y conceptuales para la discusión del problema planteado, para continuar, a partir del análisis documental de los antecedentes, con la descripción del caso de estudio.

\section{Aproximaciones teórica y conceptual}

Centralidad patrimonial. En el contexto del presente artículo, la noción de centralidad está planteada en un sentido relacional y es relativa al resto de la estructura urbana. Una centralidad urbana es aquella centralidad con un nivel importante de concentración de las funciones centrales (comercios, servicios y equipamientos, entre otros). Ahora bien, en este contexto, una centralidad patrimonial es una centralidad urbana con un alto valor de antigüedad. Tal condición reside en su especificidad histórica dotada de un sentido social particular que trasciende el conjunto de sus monumentos.

Patrimonio. La invención del patrimonio en nuestra región ha estado asociada a la emergencia de necesidades específicas en dos momentos históricos claves (Delgadillo, 2015). En un primer momento el interés por el patrimonio construido, surge a partir de los procesos de descolonización. Una vez independientes de la corona, las nuevas repúblicas se lanzan a la construcción de sus respectivas identidades nacionales, de las cuales dan fe el conjunto de sitios y monumentos históricos, que relatan la historia de conquistadores y conquistados. En un segundo momento (actual) el interés por la conservación se orienta a la necesidad de promover el patrimonio para el turismo internacional a gran escala como valor de cambio para su explotación comercial. Esos dos momentos identificados por Delgadillo, ejemplifican cómo el valor que se le asigna al patrimonio y a la necesidad de su conservación, responde a intereses de diversa naturaleza que están marcados, no sólo por el lugar (espacio), sino también por su determinismo histórico (tiempo).

Patrimonio cultural. El concepto de patrimonio cultural, ha sido enunciado por un nutrido grupo de expertos de diversas disciplinas. Para comenzar, Fernando Carrión (2013) afirma que, el monumento no está asociado a los atributos estilísticos de la obra de arte, los cuales sugieren políticas públicas limitadas a la conservación y protección del patrimonio. Un conocimiento más ampliamente comprensivo de lo patrimonial, trasciende lo físico espacial, para considerar aspectos relacionados a su capacidad de emisión simbólica. No sólo nos referimos al patrimonio cultural y natural, sino también, al patrimonio intangible, a fin de otorgar reconocimiento a la diversidad de manifestaciones culturales. García Canclini (1993) retoma el concepto de capital cultural enunciado por (Bordeau, 1979), para referirse al patrimonio cultural como un recurso no renovable. La definición es de carácter instrumental, y como tal, de un bien destinado a fines, que requiere ser utilizado para garantizar su conservación. En la misma línea argumental Harvey (2012) desarrolla el concepto de capital simbólico 
colectivo, entendido como el conjunto de prácticas culturales históricamente constituidas con características medioambientales especiales propias de un entorno construido, social y cultural. Ellas se manifiestan, no sólo en su realidad material, sino también discursiva, basadas en narrativas e interpretaciones de memorias colectivas. El poder de atracción de este capital simbólico, constituye las marcas de distinción y singularidades no reproducibles que distingue a cada uno de estos conjuntos. Aquí, la cuestión fundamental planteada por el autor reside en determinar qué sectores de la población se van a beneficiar de ese capital simbólico colectivo al que todos han contribuido (Harvey, 2012). La producción popular de bienes comunes urbanos con su capital simbólico acumulado son con frecuencia apropiados no sólo por los promotores inmobiliarios, sino por el sector turístico a través de dinámicas de gentrificación, cuya naturaleza selectiva produce intensas disputas territoriales devenidas de la acción ciudadana.

Turismo cultural. El turismo cultural es un tipo de turismo orientado al consumo de cultura por parte de los visitantes. La cultura es comprendida como el conjunto de creencias, valores y estilos de vida de las personas en su existencia cotidiana. Esta tendencia de consumo turístico es reciente y se encuentra en plena expansión. El turista cultural es selectivo y se caracteriza, no sólo por el interés de conocer los monumentos y sitios patrimoniales, sino también, por impregnarse de la cultura de destino. La degustación de la comida local, la experiencia existencial del espacio público compartido, el clima popular son, entre otros, algunos de sus placeres.

En México, una de las modalidades de estancia del turista, se caracteriza por la decisión de reemplazar la habitación del hotel, por una residencia temporal en el país. Esta modalidad, denominada de segundas residencias, permite al turista procedente del extranjero, vivir temporalmente, tanto en México, como en su país de origen. Caracterizan esta modalidad, tanto el turismo de playa como el turismo cultural. En este último caso, el turista atraído por el ambiente local urbano, renta o compra una vivienda en el país de destino, la cual se localiza, si no al interior, en las cercanías de enclaves patrimoniales. Este tipo de turismo tiene determinantes sociales y económicos distintivos. Se trata mayoritariamente, de los denominados baby boomers norteamericanos, representados por un segmento de población de la tercera edad, transitando la etapa no productiva de la vida (jubilados y pensionados). En tales circunstancias, eligen un lugar para residir, que ofrezca condiciones de calidad de vida comparativamente más convenientes que aquellas de sus lugares de origen. En términos económicos, la residencia que adquieren en México, resulta más barata, si tenemos en cuenta la tasa de cambio imperante entre la moneda mexicana y la norteamericana, como así también, un costo de vida significativamente menor, habida cuenta del mayor poder adquisitivo del dólar. Este tipo de turismo no es aleatorio sino, que se relaciona con el conocimiento previo y la experiencia del turista en la región de destino. Dicha experiencia, se sustenta en una cultura migratoria consolidada entre México y Estados, cuyos flujos se constatan de manera creciente, en ambos sentidos. Residir en viviendas tradicionales de arquitectura vernácula, emplazadas en entornos urbanos de gran valor patrimonial, constituye un atractivo suficiente para el desarrollo de una nueva forma de turismo residencial (Enriquez y Méndez, 2012).

Gentrificación. Neil Smith (1996), desarrolla la teoría de la gentrificación, como parte de lo que denomina el "urbanismo revanchista" de fin de siglo, 
orientado a una recuperación del centro de la ciudad por las clases altas anglosajonas. Se trata, de una reconstrucción clasista del paisaje del centro urbano. La movilidad de habitantes y la puesta en valor de zonas de bajo costo adquisitivo son los dos aspectos involucrados en el fenómeno de la gentrificación. En estos procesos, por un lado, son expulsadas las poblaciones de bajos recursos que habitan el centro de la ciudad y por otro, nuevas poblaciones mejor posicionadas regresan al centro, estimulados por una nueva valoración de la cultura urbana.

Sin embargo, algunos autores (Casgrain y Janoshka, 2013, Coulomb, 2014) coinciden en que esta acepción del término, propia de países anglosajones y europeos, debe ser contrastada críticamente con la realidad de las ciudades latinoamericanas, a fin de evaluar la pertinencia de su aplicación para el análisis de otras realidades, cuya complejidad requiere ampliar sus confines conceptuales.

El turismo, en su nueva condición de agente gentrificador, expulsa de manera creciente y sistemática a su población residente. A diferencia de la gentrificación entendida como proceso de sustitución de una clase social por otra (Smith, 1996), el turista se caracteriza por su condición flotante, y en tal sentido, no sólo expulsa a la población residente, sino que, no la sustituye. Ello es así, porque las actividades del turista, habida cuenta de: a. la temporalidad de su residencia, y b. la naturaleza de sus prácticas, no construye capital social.

Turismo y capital social. La condición visitante del turista le impide en la mayoría de los casos, establecer relaciones de largo alcance, y en tal sentido, su residencia provisoria resulta insuficiente para la construcción de redes permanentes que generen confianza social. Queda claro que, la disposición del turista a establecer prácticas sociales duraderas, es escasa, habida cuenta de su permanencia efímera en el lugar.

Para una posible explicación del perfil del turista como actor social, nos apoyaremos en la teoría del capital social. Uno de sus principales exponentes, Alessandro Pizzorno (2003) indaga sobre la naturaleza de las acciones sociales que construyen capital social y para ello precisa los rasgos que las distinguen de otras acciones sociales. Comienza por excluir los tipos de relaciones sociales que obviamente no pueden constituir capital social, analizando lo que tienen en común. No lo son, nos dice, las relaciones de intercambio, las de mero encuentro entre personas que no continúan su relación, ni las de hostilidad, explotación o conflictivas en general. Son sus rasgos distintivos, que no necesitan ser reconocidas por la identidad del otro, o que intentan anular la identidad del otro (Pizzorno, 2003). En consecuencia son portadoras de capital social aquellas relaciones en las que es posible que la identidad más o menos duradera de los participantes sea reconocida, y que además imaginen formas de solidaridad 0 reciprocidad. En este contexto explicativo queda claro que, las relaciones de nuestro protagonista principal, el turista, reúnen las dos primeras condiciones que le impiden generar capital social: relaciones de intercambio y de mero encuentro entre personas que no continúan su relación, y en tal sentido, no están determinadas por el reconocimiento de la identidad de los actores que participan en la interacción.

Procesos migratorios. Un sistema migratorio se podría definir como "(...) dos o más lugares (países) unidos por flujos y contraflujos de gente. Dentro de estos sistemas el comercio, las relaciones de tipo político u otras, así como las relaciones estrictamente coloniales crean las bases que 
dan origen y dirección a los fenómenos migratorios (Martínez Veiga, 2000).

La intensidad migratoria se manifiesta en el volumen de los flujos migratorios, sólo viables a partir de una cultura migratoria consolidada, construida mediante redes sociales y familiares de largo arraigo en Estados Unidos. Sin embargo, los procesos migratorios no son homogéneos y en ellos se distinguen diversos patrones de movilidad relacionados con: la frecuencia, la temporalidad y el alcance (número de miembros de la familia que emigra).

El proceso migratorio resulta de las desigualdades socio espaciales que se reproducen en forma constante, expresa Martínez Veiga (2000). El desarrollo capitalista desplaza a la gente de sus sistemas tradicionales de vida hacia destinos diferentes de su lugar de origen, estableciendo dinámicas circulares, interdependientes y complejas donde se juntan los sistemas sociales de origen y de destino, como es el caso de las comunidades transnacionales que aquí nos ocupa. La inmigración extranjera transforma la realidad socio espacial de la localidad de acogida, ya que introduce diversidad social, cultural, étnica, entre otras, en la vida cotidiana.

\section{San Miguel de Allende: claves para su comprensión}

A nivel de municipal, San Miguel de Allende refleja la misma situación de crecimiento desequilibrado propio de otras regiones de Guanajuato y del país. Una alta concentración de población en áreas urbanas, sustenta su economía, en actividades terciarias orientadas al comercio y servicios turísticos. En contraste, una gran dispersión de población en localidades rurales menores a los 2.500 habitantes, son expulsoras de población hacia Estados Unidos (Flores Pacheco et al., 2016).

En la ciudad de San Miguel de Allende identificamos dos cualidades destacables. Por una parte, la calidad de su patrimonio edificado, atributo que le mereció en el año 2010, el título de Ciudad Patrimonio Mundial, mismo que incluye al Santuario de Atotonilco. Por la otra, su potencial migratorio, evidenciado en una importante población de extranjeros de mediana edad, que residen actualmente en la ciudad. Abordaremos cada una de estas claves en forma desagregada.

\section{La cuestión territorial: el Centro Histórico}

El Centro Histórico de San Miguel de Allende, destaca por la calidad y densidad de su patrimonio edificado, representado por un importante acervo de arquitectura virreinal. Las calles empedradas y plazas de la ciudad colonial, celebran actividades artísticas y culturales, las cuales infunden un ambiente urbano grato y especial. Todo ello, le ha valido el reconocimiento de uno de los destinos turísticos más relevantes a nivel estatal y regional.

La necesidad de reconfigurar en forma constante la delimitación de los centros históricos se ha dado en dos sentidos diferentes: a la luz de la ampliación de los confines conceptuales de patrimonio, que hace posible se definan e incorporen nuevas tipologías patrimoniales (cultural/natural, tangible/intangible); como así también, a través de la ampliación constante de cada uno de sus catálogos, que incorpora nuevos monumentos consagrados con el paso del tiempo. En tal contexto, el Centro Histórico de San Miguel de Allende ha sido sucesivamente delimitado, en función de la 
ampliación creciente del catálogo de monumentos del centro a la periferia y en

conformidad con la densidad del patrimonio edificado (Fig. 1).

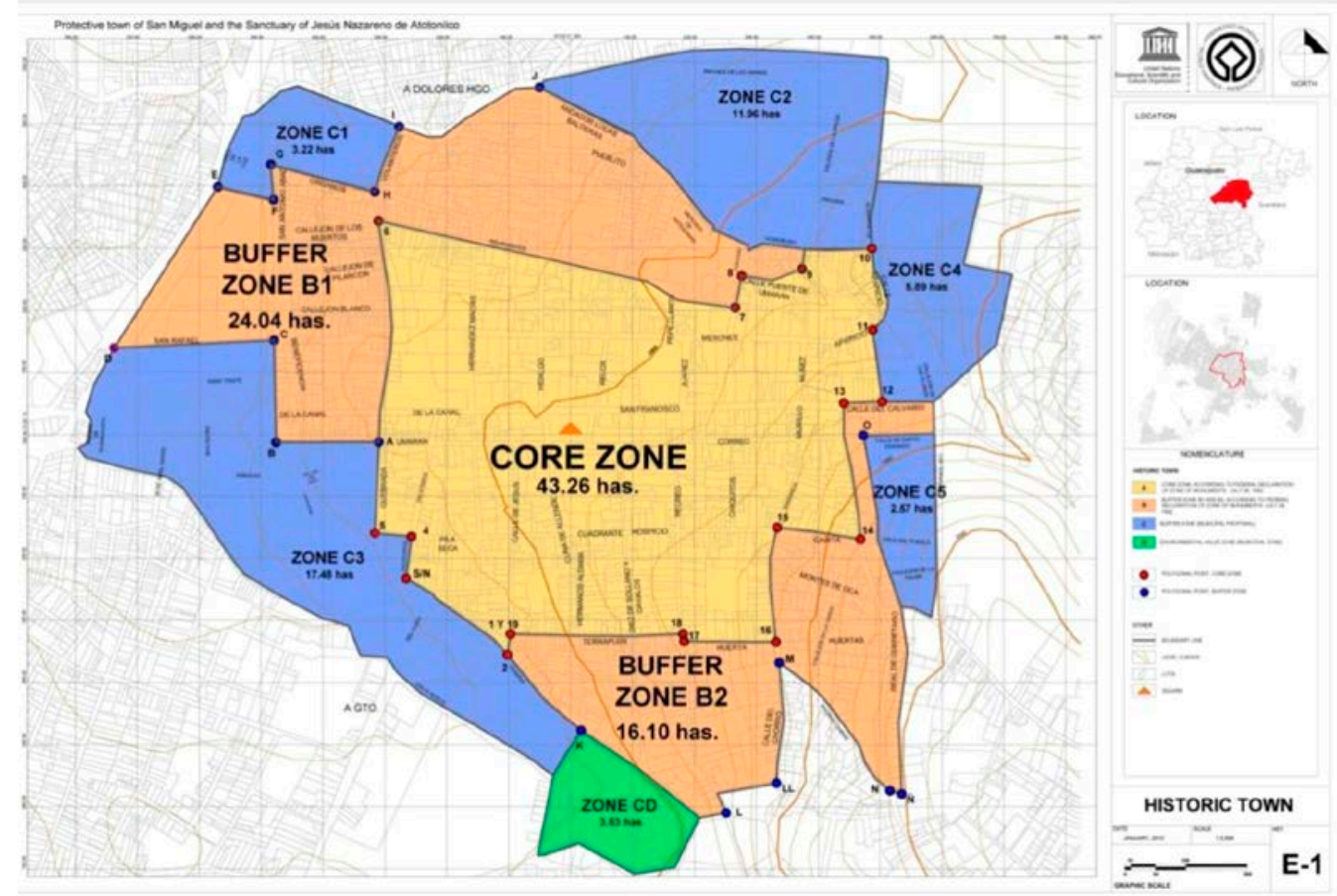

Figura 1. Zona de Monumentos Históricos, así como la comprendida en la Declaratoria de Patrimonio Mundial Fuente: Reglamento del Código Territorial del Municipio de San Miguel de Allende, Gto.

En 1982 se delimitan dos perímetros, a saber:

$\checkmark$ Perímetro A, donde se encuentra la mayor parte de los monumentos catalogados.

$\checkmark$ Perímetros B1 y B2, donde el número y densidad de monumentos catalogados son menores, considerándose como zona de transición o amortiguamiento.

$\checkmark$ Perímetro $\mathrm{C}$ que es principalmente una zona de transición y amortiguamiento entre las fracciones A y B decretadas como Zona de Monumentos Históricos y el resto de la ciudad.

$\checkmark$ Perímetro D corresponde al área del parque Benito Juárez, por representar un área de valor ambiental y sociocultural importante dentro de la ciudad.

En tal sentido, Mestre Martí y Castillo Mena (2017), expresan la necesidad de trascender los límites administrativos que definen el contorno de una centralidad, para desarrollar una visión integral de la ciudad, a cuya estructura pertenece, como así también, hacer funcionales y compatibles el conjunto de recursos orientados a un mismo fin (Mestre Martí et al., 2017).

Numerosos planes de conservación se han implementado desde entonces: (Plan parcial (1997), Plan de Desarrollo Turístico (2003), Plan de ordenamiento territorial de población (1998-2000) y Plan Parcial del CH de SMA (2003), orientados en su mayoría a una visión conservacionista del patrimonio edificado, sin considerar el valor de su capital simbólico colectivo (Harvey, 2012), es decir, el conjunto de prácticas sociales históricamente constituidas, que le dan sentido y le confieren atributo de ciudad, dentro de la ciudad en su conjunto. 


\section{La cuestión social: el potencial migratorio}

Según el Consejo Nacional de Población (CONAPO, 2015), los estados que registran mayor índice de intensidad migratoria son cuatro y pertenecen a la región tradicionalmente expulsora de migrantes a ese país: Zacatecas (4.422), Guanajuato (3.891), Michoacán (3.868) y Nayarit (3.370). Sin embargo, en el estado de Guanajuato, se registraron 18.359 extranjeros en el año 2000, población que se incrementó a 39.207 en 2010 (Fig. 2).

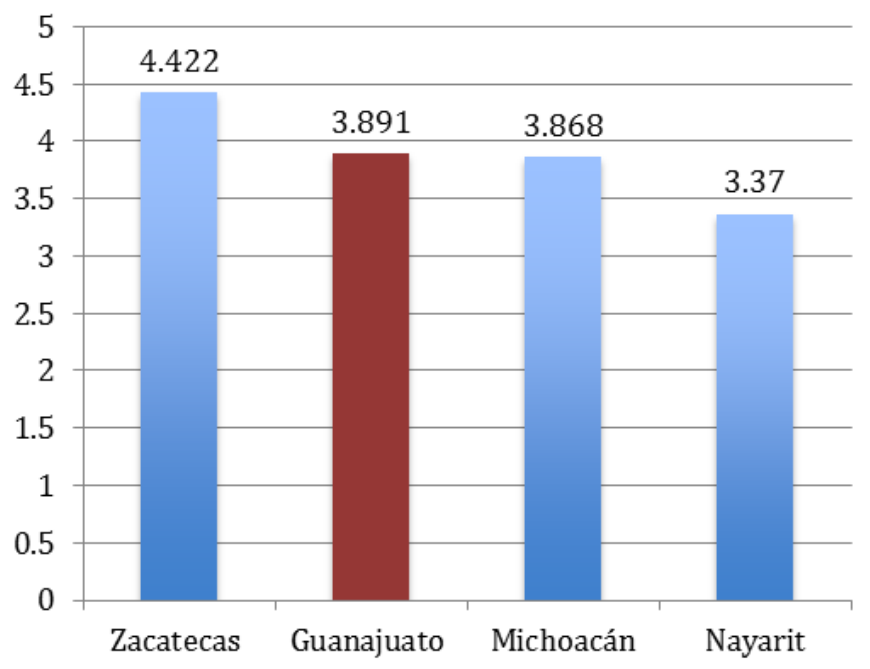

Figura 2. Índice de Migración 2010. Fuente: elaboración propia en base a datos de Consejo Nacional de Población CONAPO 2015

La cantidad de extranjeros se duplicó en una década, según datos del Instituto Nacional de Migración. Esta tendencia creciente promete acentuarse en los próximos años con la llegada de empresas trasnacionales del clúster automotriz que tiende a consolidarse en el Bajío, principalmente de Estados Unidos, Japón, Alemania e Italia.

Ahora bien, el Estado de Guanajuato se caracteriza por importantes corrientes migratorias de doble sentido. Por un lado, expulsa población local hacia Estados Unidos, a la vez que ingresan en su territorio grupos de inmigrantes extranjeros de origen estadounidense $\quad y \quad$ canadiense mayoritariamente.

A nivel municipal San Miguel de Allende, acusa intensidad migratoria en los dos sentidos señalados. Por un lado, expulsa de manera creciente la población que habita en localidades dispersas de población rural o desocupada, hacia Estados Unidos en busca de oportunidades laborales que ofrezcan mejores ingresos. Esta dinámica crea un mercado de la tierra donde predomina la poca regulación y la especulación inmobiliaria, con marcados contrastes entre el crecimiento inmobiliario aledaño a la cabecera y el desarrollo de las localidades en el resto del municipio. Por otro lado, San Miguel de Allende es uno de los municipios en el país que concentra mayor número de extranjeros, quienes eligen mayoritariamente residir en su Centro Histórico. Actualmente, la localidad tiene una población de 160.000 habitantes, de los cuales 13.000 (8.12 \%) son de origen extranjero, principalmente de Canadá y Estados Unidos, además de algunos italianos, suizos, ingleses, franceses, entre otros; y en su mayoría son retirados, de la generación conocida como baby boomers (hoy jubilados de la tercera edad). Se estima que alrededor de $80 \%$ del Producto Interno 
Bruto (PIB) de San Miguel de Allende depende del turismo, y de este

porcentaje, $50 \%$ lo genera la comunidad

\author{
extranjera (figura 3).
}

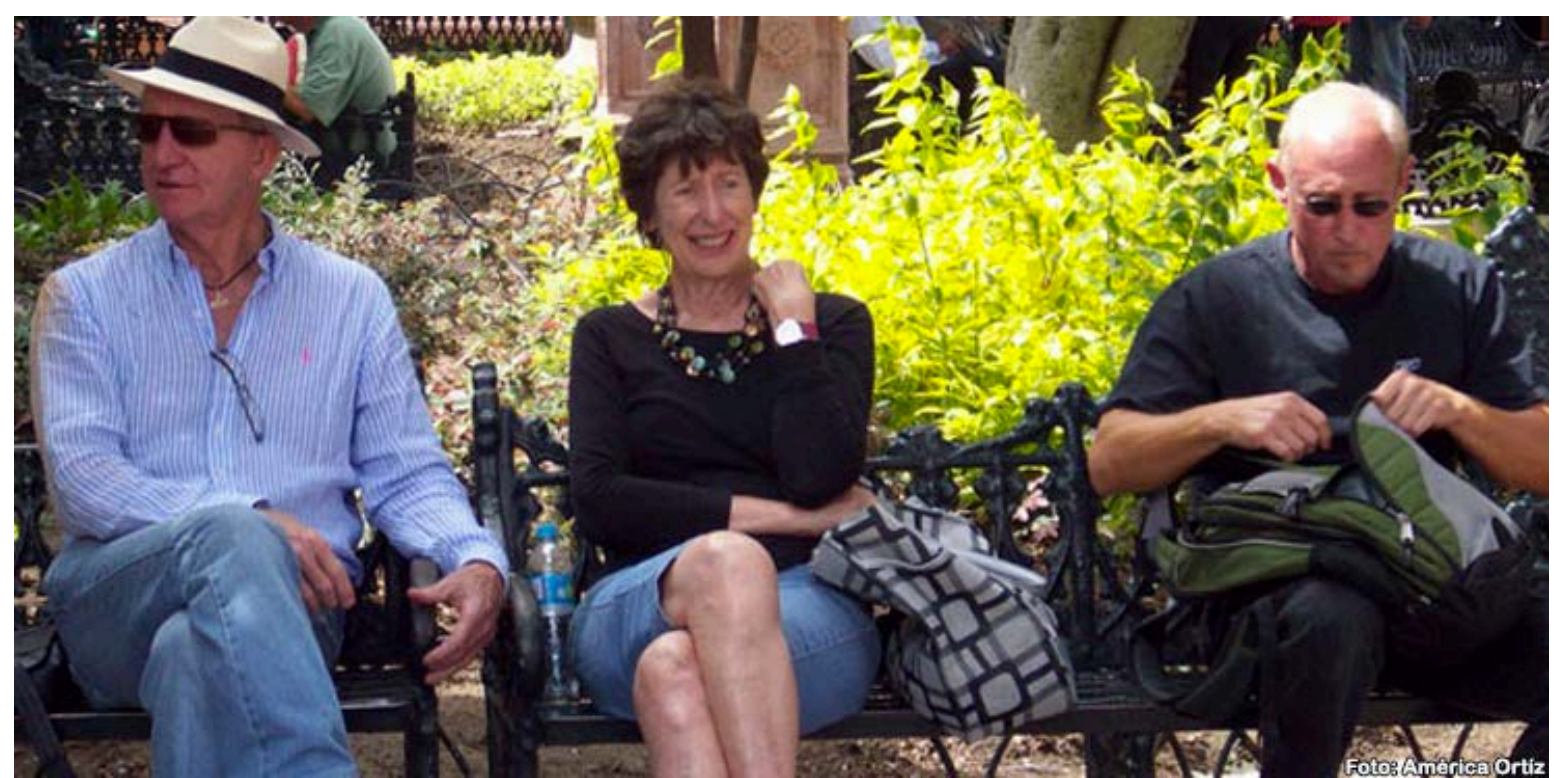

Figura 3. Comunidad extranjera en San Miguel de Allende. Fuente: http://www.ciudadypoder.mx/

Si se analiza la evolución de la relación entre los residentes locales y extranjeros en las últimas décadas, se advierte en promedio, una tendencia creciente. Entre 1980/1990 el porcentaje de crecimiento de ambos tipos de residentes es equivalente (40\%). Distinto es el caso de la década siguiente (1990/2000), en que los residentes locales crecen $37 \%$, mientras que, el porcentaje de residentes extranjeros disminuye 50\%, marcando una relación inversa entre ambos grupos. La relación se invierte en la década 2000/2010, período en que se registra un crecimiento inferior a $1 \%$ de los residentes locales (prácticamente se mantiene), frente a $185 \%$ de crecimiento de residentes extranjeros. La figura 4 da cuenta de la evolución de la relación de ambos tipos de residentes, aunque sólo se registran datos a partir de 1980 .

Sin embargo, tal como expresáramos anteriormente, tres generaciones de extranjeros llegaron a San Miguel de
Allende entre el siglo XX y XXI. Los fenómenos migratorios (centrífugos $\mathrm{y}$ centrípetos) para el caso de San Miguel de Allende, no parecen poder explicarse sólo desde la teoría clásica de la migración, la cual afirma que, es el diferencial en salarios entre países receptores y emisores, así como la tendencia al equilibrio en los salarios a partir de los procesos migratorios, la causa que los motiva.

Para ello, es necesario introducir otras variables que no son estrictamente económicas, tales como la "utilidad del lugar” entendida como la atracción que un lugar o espacio ofrece para un individuo. En ellas están comprendidos aspectos como la salud, la seguridad, el entorno urbano, etc. Sin embargo, los desequilibrios existentes en los mercados de trabajo en diferentes países, determina las diferencias del poder adquisitivo de los salarios, entre uno y otro lugar, lo cual induce a los individuos a tomar decisiones a emigrar a zonas con una 
mayor utilidad. (...) la migración rectifica los desequilibrios salariales ” (Martínez
Veiga, 2000)

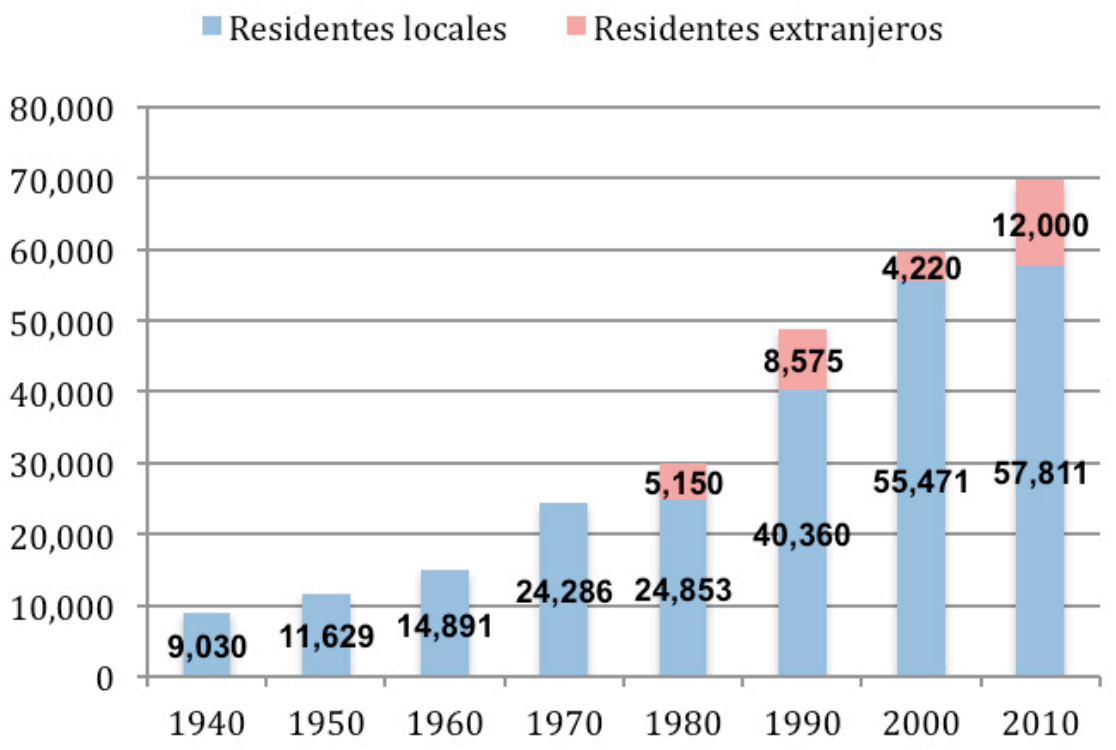

Figura 4: Evolución de la población en San Miguel de Allende. Fuente: elaboración propia con datos de INEGI Instituto Nacional de Estadística y Geografía (INEGI) e Instituto Nacional de Migración (INM).

Los fenómenos migratorios (centrífugos y centrípetos) para el caso de San Miguel de Allende, no parecen poder explicarse sólo desde la teoría clásica de la migración, la cual afirma que, es el diferencial en salarios entre países receptores y emisores, así como la tendencia al equilibrio en los salarios a partir de los procesos migratorios, la causa que los motiva.

Para ello, es necesario introducir otras variables que no son estrictamente económicas, tales como la "utilidad del lugar” entendida como la atracción que un lugar o espacio ofrece para un individuo. En ellas están comprendidos aspectos como la salud, la seguridad, el entorno urbano, etc.

Sin embargo, los desequilibrios existentes en los mercados de trabajo en diferentes países, determina las diferencias del poder adquisitivo de los salarios, entre uno y otro lugar, lo cual induce a los individuos a tomar decisiones a emigrar a zonas con una mayor utilidad. (...) la migración rectifica los desequilibrios salariales ” (Martínez Veiga, 2000).

Tres olas migratorias

En San Miguel de Allende, se identifican tres olas migratorias correlativas y bien diferenciadas por su temporalidad, motivaciones y composición, a saber:

En los años 40 del siglo XX, a partir del programa Gil Bill, la ciudad de San Miguel de Allende se convirtió en centro de atracción de miles de jóvenes norteamericanos y canadienses, dispuestos a estudiar en el recientemente fundado Instituto Allende, escuela de arte de prestigio internacional. Dicho programa de becas, promovido por el gobierno de Estados Unidos, fue asignado a los 
veteranos de la Segunda Guerra Mundial y la Guerra de Corea, para realizar estudios técnicos y universitarios en el extranjero (Flores Pacheco et al., 2016). Durante las décadas, del 50 y 60 del siglo pasado, la localidad se consolida como centro cultural a partir de la presencia de connotadas personalidades extranjeras y nacionales vinculadas al arte y la cultura. A ellas, se sumarían importantes iniciativas locales orientadas a poner en valor el patrimonio edificado (Ferro de la Sota, 2012).

Una segunda generación de extranjeros irrumpe a partir de los años 80 del siglo pasado, integrada por jubilados e inversionistas estadounidenses atraídos por las condiciones favorables de un lugar apacible, no sólo para visitar, sino también, para retirarse e invertir, esto último, en restaurantes, bienes inmuebles, hoteles, entre otros. La década de los noventa, caracterizada por el flujo de capitales externos y la afluencia turística, produce un incremento poblacional, cambios en las dinámicas sociales y una nueva reconfiguración del territorio urbano.

En el presente siglo, la tercera ola de extranjeros y la más reciente, está representada por inversionistas privados, cuya vocación mercantil, es compartida por un nutrido sector de mexicanos con recursos económicos dispuestos para invertir en la localidad. El impacto en la ocupación territorial, se manifiesta en fuertes inversiones en infraestructura hacia Dolores Hidalgo, donde abundan las tierras ejidales con potencial agrícola, además de que existen mantos acuíferos de aguas termales, atractivos para la inversión. El crecimiento urbano de población extranjera, excede los límites de la centralidad histórica, para expandirse más allá de sus confines, con segundas residencias dispersas en extensas parcelas retiradas de la carretera principal. Son los mismos actores sociales que frecuentan y a menudo invierten en el Centro Histórico. Esta nueva generación, se manifiesta desarraigada $\mathrm{y}$, en tal sentido, menos propensa a integrarse a la cultura local. En consecuencia, es percibida, por el residente local, como la más intrusiva y con una marcada actitud etnocentrista, situación que provoca frecuentes reacciones xenofóbicas (Flores Pacheco et al., 2016) (ver figura 5).

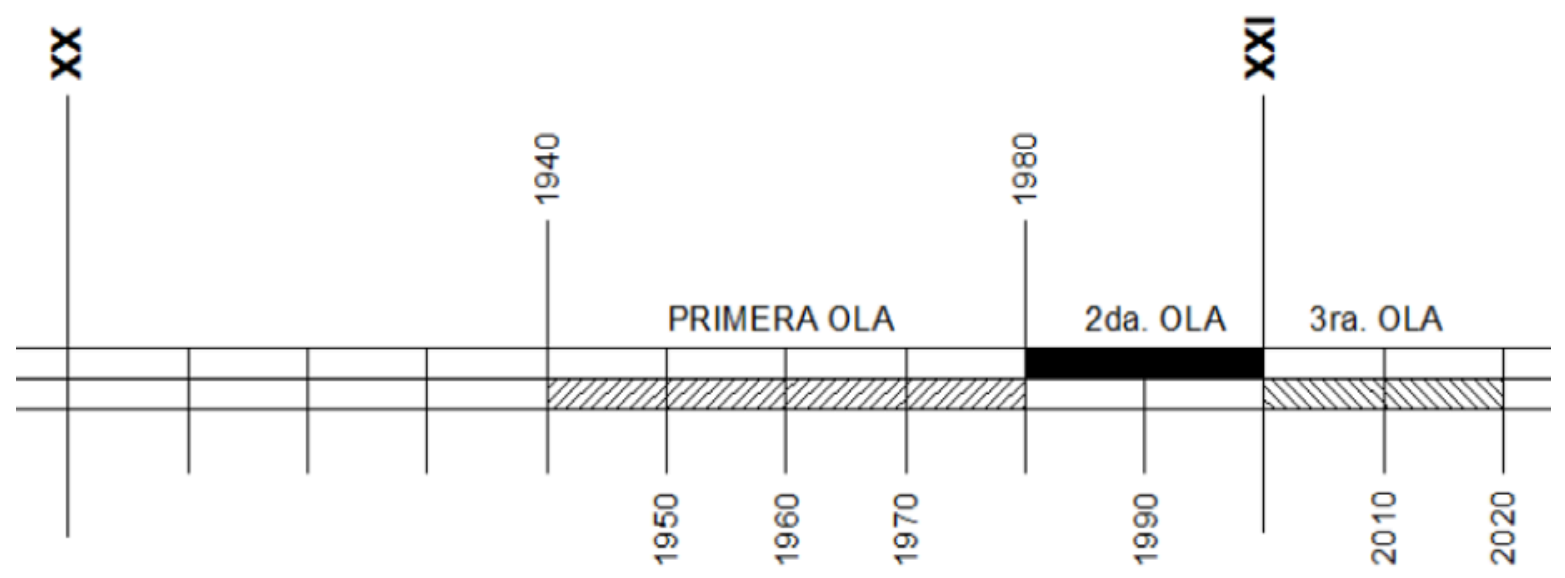

Figura 5. Línea temporal de las olas migratorias en San Miguel de Allende. Fuente: Elaboración propia

Las olas migratorias, hasta aquí descritas difieren entre sí, no sólo por sus motivaciones, sino también, por el grupo etario de extranjeros que las compone y su 
grado de integración a la cultura local.

\section{Conclusiones}

La localidad de San Miguel de Allende representa un caso atípico de centralidad en el contexto estatal, en virtud de su alto valor de antigüedad y, en tal sentido, la calidad de su patrimonio edificado, como así también, del desarrollo de una cultura artística local de antiguo arraigo. Esta condición la hizo atractiva para una población mayoritariamente extranjera que ha colonizado de manera creciente su Centro Histórico y áreas periféricas con diversos fines. Dicha situación es promovida por la cultura migratoria consolidada en la región, la cual acusa una intensidad variable en ambos sentidos. San Miguel de Allende es elegida por un conjunto de comunidades extranjeras para vivir, a la vez que, los sanmiguelenses migran a Estados Unidos, obligados por su condición de marginalidad económica y escasas oportunidades de desarrollo social en su lugar de origen.

En el primer caso, los turistas pierden su condición de visitantes temporales para convertirse en residentes permanentes. Esta condición la adquieren, a partir de la adquisición de una vivienda, ya sea de primera o de segunda residencia. Cualquiera sea el caso, el impacto en el medio local es de un tipo de gentrificación que denominamos por migración, en tanto y en cuanto, los nuevos migrantes conforman una nueva clase social diferente, con sus propios valores y legados culturales de origen, que tiende a sustituir y desplazar territorialmente a la población residente local.
Ahora bien, los procesos de exclusión social a partir de las dinámicas de gentrificación, tienen en el Centro Histórico de San Miguel de Allende una doble lectura. Por una parte, la llegada de una importante población de extranjeros, con recursos suficientes para hacerse de bienes inmuebles de valor patrimonial (devaluados por su escaso o nulo mantenimiento), desplazando a la población residentes local de menores recursos: gentrificación por migración. Por otra parte, la llegada de una población flotante (extranjeros y nacionales) cuyas actividades demandan un conjunto de nuevos servicios (multiplicación de hoteles, comercios y equipamientos para visitantes), se apropia del Centro Histórico. Sus efectos negativos en términos socioeconómicos desplaza al residente y usuario original: genttrificación turística.

Estos procesos simultáneos implican una pérdida del capital social originario en un doble sentido. En primer lugar, irrumpen nuevas formas de capital social que construyen actores sociales culturalmente no integrados a los valores locales por su condición foránea. En segundo lugar, la presencia permanente de una población trashumante (turistas) que no construye capital social, por su condición transitoria.

Estas son conclusiones provisionales que derivan de la exploración documental de antecedentes del caso, como así también, de la interpretación del mismo, a la luz de los postulados teóricos iniciales. 


\section{Referencias}

Bourdieu, Pierre. 1979. Les trois états du capital culturel, en Actes de la Recherche en Sciences Sociales, 30, pp. 3-6.

Carrión, Fernando. 2013. "El patrimonio histórico y la centralidad urbana”. En B. R. Ramírez Velázquez, Teorías sobre la ciudad en América Latina, págs. 709-740. México: Universidad Autónoma Metropolitana.

Casgrain, Antoine y Michael Janoschka 2013. Gentrificación y resistencia en las ciudades latinoamericanas. El ejemplo de Santiago de Chile. En Andamios, Volumen 10, número 22, mayo-agosto: 19-44.

Coulomb, Rene. 2014. "Construyendo utopías desde el centro”. En Hábitat popular en los centros antiguos de Iberoamérica, editados por Mesías Suarez Paredón y Víctor Delgadillo, 16-28. México: CYTED/CENVI.

Delgadillo, Víctor. 2015. "Patrimonialización de la herencia colonial”. En Ciudades. Centro histórico: criterios de análisis e intervenciones. $\mathrm{N}^{\circ} 107,8-15$.

Enriquez, Jesús y Méndez, Eloy. 2012. "Introducción”. En Jesús Enríquez y Eloy Méndez (coords.) De itinerarios, paisajes e imaginarios. Miradas y acercamientos al estudio del turismo, págs. 5-10, Hermosillo: Universidad de Sonora.

Ferro de la Sota, Hernán. 2012. "Proceso de apropiación del suelo en el Centro Histórico de una ciudad atípica. Caso de San Miguel de Allende, 1950-2008”. En Coloquios II de Investigación sobre Arquitectura, coordinado por Miguel Ángel García Gómez, 68-81. México: Universidad de Guanajuato.

Flores Pacheco, Martha Inés y Martha Patricia Guerra Vallejo. 2016. “Entre lo local y lo foráneo: Gentrificación y discriminación en San Miguel de Allende, Guanajuato”. En Revista Legislativa de Estudios Sociales y de Opinión Pública, vol. 9, núm. 18: 183-206, Cámara de Diputados LXIII Legislativa y Centro de Estudios Sociales y de Opinion Pública.

García Canclini, Néstor. 1993. "Los usos culturales del patrimonio". En E. Florescano (Comp.) El patrimonio cultural de México, F.C.E.: México

Harvey, David. 2012. Ciudades rebeldes. Del derecho a la ciudad a la revolución urbana. España: Akal.

Martínez Veiga, Ubaldo. 2002. “Teorías sobre las migraciones”. En Migraciones \& Exilios: Cuadernos de la Asociación para el estudio de los exilios y migraciones ibéricos contemporáneos, $\mathrm{N}^{\circ}$ 1: 11-26.

Mena. Mestre Martí, María y Alicia Castillo medioambientales para una mejor gestión del patrimonio cultural en cuatro ciudades del Caribe: La Habana, San Juan Viejo, Santo Domingo y Cartagena de Indias”. En ACE, 11(33): 87-116 (en línea) Consulta: 15 jun. 2017. DOI: 10.5821/ace.11.33.4784. ISSN: 1886-4805.

Pizzorno, Alessandro. 2003. "Por qué pagamos la nafta. Por una teoría del capital social”. En A. Bagnasco, F. Piselli, A. Pizzorno y C. Trigilia. El capital social. Instrucciones de uso. México: FCE

Smith, Neil 1996. The Nex Urban Frontier: Gentrification and the Revanchist City. Nueva York: Routledge. 